\title{
Development of an integrated, district-wide approach to pre-pregnancy management for women with pre-existing diabetes in a multi-ethnic population
}

Maryam Sina, Freya MacMillan, Tinashe Dune, Navodya Balasuriya, Nouran Khouri, Ngan Nguyen,

Vasyngpong Jongvisal, Xiang Hui Lay and David Simmons*

\begin{abstract}
Background: Poor diabetes management prior to conception, results in increased rates of fetal malformations and other adverse pregnancy outcomes. We describe the development of an integrated, pre-pregnancy management strategy to improve pregnancy outcomes among women of reproductive age with diabetes in a multi-ethnic district.

Methods: The strategy included (i) a narrative literature review of contraception and pre-pregnancy interventions for women with diabetes and development of a draft plan; (ii) a chart review of pregnancy outcomes (e.g. congenital malformations, neonatal hypoglycaemia and caesarean sections) among women with type 1 diabetes (T1D) $(n=53)$ and type 2 diabetes (T2D) $(n=46)$ between 2010 and 2015 (iii) interview surveys of women with T1D and T2D ( $n=15)$, and local health care professionals $(n=13)$; (iv) two focus groups $(n=4)$ and one-to-one interviews with women with T1D and T2D from an Australian background $(n=5)$, women with T2D from cultural and linguistically diverse (CALD) $(n=7)$ and indigenous backgrounds $(n=1)$ and partners of CALD women $(n=3)$; and (v) two group meetings, one comprising predominantly primary care, and another comprising district-wide multidisciplinary inter-sectoral professionals, where components of the intervention strategy were finalised using a Delphi approach for development of the final plan.
\end{abstract}

Results: Our literature review showed that a range of interventions, particularly multifaceted educational programs for women and healthcare professionals, significantly increased contraception uptake, and reduced adverse outcomes of pregnancy (e.g. malformations and stillbirth). Our chart-review showed that local rates of adverse pregnancy outcomes were similarly poor among women with both T1D and T2D (e.g. major congenital malformations [9.1\% vs 8.9\%] and macrosomia [34.7\% vs 24.4\%]). Challenges included lack of knowledge among women and healthcare professionals relating to diabetes management and limited access to specialist pre-pregnancy care. Group meetings led to a consensus to develop a district-wide approach including healthcare professional and patient education and a structured approach to identification and optimisation of self-management, including contraception, in women of reproductive age with diabetes.

Conclusions: Sufficient evidence exists for consensus on a district-wide strategy to improve pre-pregnancy management among women with pre-existing diabetes.

Keywords: Pre-pregnancy care, Contraception, Type 1 diabetes, Type 2 diabetes, Intervention programs, Malformations

\footnotetext{
* Correspondence: Da.Simmons@westernsydney.edu.au

Western Sydney University, Sydney, NSW 2751, Australia
}

(c) The Author(s). 2018 Open Access This article is distributed under the terms of the Creative Commons Attribution 4.0 International License (http://creativecommons.org/licenses/by/4.0/), which permits unrestricted use, distribution, and reproduction in any medium, provided you give appropriate credit to the original author(s) and the source, provide a link to the Creative Commons license, and indicate if changes were made. The Creative Commons Public Domain Dedication waiver (http://creativecommons.org/publicdomain/zero/1.0/) applies to the data made available in this article, unless otherwise stated. 


\section{Background}

Women with type 1 and type 2 diabetes have a high risk of adverse pregnancy outcomes, especially when conception is unplanned [1]. Uncontrolled hyperglycaemia before and during pregnancy leads to adverse maternal and foetal outcomes [2]. Pre-pregnancy care (PPC) includes services aimed at managing glycaemia, education on diabetes complications in pregnancy, screening and treatment of diabetic complications, management of medications, and the supplementation of higher-dose folic acid required by women of reproductive age to ensure higher chances of an uncomplicated pregnancy [3]. A meta-analysis in 2012 showed that across 12 studies, PPC was effective in reducing congenital malformation [Risk Ratio $(R R)=0.3(95 \%$ CI $0.2,0.4)]$ and perinatal mortality $[R R=0.3$ (95\% CI 0.2 , 0.8)] [3]. PPC was associated with a lower HbA1c in the first trimester of pregnancy by an average of 1.9\% (95\% CI: - 2.1, - 1.8) or $20.8 \mathrm{mmol} / \mathrm{mol}$ (95\% CI: - 23.0, - 19.7) [3].

However, these studies showing reduced malformations and perinatal mortality have come from clinics established for women who are planning pregnancy, and are willing and able to attend $[4,5]$. Lack of information and practical constraints, such as commitment to work, are often major obstacles for those who do not attend pre-pregnancy clinics [6]. Furthermore, approximately $50 \%$ of pregnancies among women with pre-existing diabetes remain unplanned [7, 8], and many of these should therefore be seen as largely a failure of contraception rather than a failure of access to a pre-pregnancy clinic. However, a proportion of these 'unplanned' pregnancies occur among women who wish to maintain autonomy during the pregnancy process [9], and who would not attend a pre-pregnancy clinic. It is clear that a pregnancy in a woman with diabetes without PPC is often a failure of 'the system', although at times this may be due to the failure of clinicians to understand the perspective of women with diabetes. In fact, the term "PPC" could be misleading as it implies that women are planning pregnancy, when all that may be required is effective contraception or knowledge about the options and methods of their use. Therefore, we use the term 'pre-pregnancy management' (PPM), to emphasize the integrated approach required to improve contraception uptake and pregnancy outcomes in this population.

There have been a variety of interventions at a population level that could be used for PPM, including better contraception choices, in order to reach women who have not traditionally attended pre-pregnancy clinics [5, 1013]. However, no population-based intervention program has been implemented in Australia. South West Sydney (SWS) is a home to women from culturally and linguistically diverse (CALD) backgrounds who may have different risks to women participating in previous population based approaches, requiring additional or different PPM $[1,14]$. We now present the steps in the development of an intervention program for PPM, including enhanced contraception uptake, for the multiethnic district of SWS.

\section{Methods}

The development of the intervention involved: 1) a narrative literature review of PPC intervention programs used in women with type 1 diabetes (T1D) and type 2 diabetes (T2D); 2) chart review of women with T1D and T2D; 3) interview surveys with women with T1D and T2D and health care professionals (HCPs); 4) in-depth qualitative exploration of local pregnancies through focus groups one-to-one interviews with women with T1D and T2D and partners; 5) the preparation of a draft intervention plan with discussion at a local conference; and 6) a discussion of the intervention at two multidisciplinary meetings one, predominantly primary care $(n=15)$ and one predominantly secondary care (e.g. general practitioners, obstetricians, midwives, endocrinologists, diabetes educators, dietitians) $(n=17)$ to finalise the plan.

\section{Narrative review}

Google Scholar, PubMed and Medline databases were searched for randomised trials (including cluster and quasi-randomised trials), as well as cohort and case-control studies assessing the impact of PPC programs on women's knowledge of the components of PPC and the use of contraception and/or their pregnancy outcomes (Fig. 1). Studies investigating solely the effect of (a) pre-pregnancy clinics on pregnancy outcomes, as opposed to the effect of other interventions (e.g. leaflets, posters) were not included [3]. The search strategy included the following keywords: "pre-conception care" or "intervention programs" or "contraception" or "contraception uptake" or "pre-pregnancy care" AND "negative pregnancy outcomes" or "adverse pregnancy outcomes" or "pregnancy complications" AND "type 2 diabetes" or "type 1 diabetes" or "diabetes". Only full-text journal articles in English of studies that assessed the impact of PPC programs on women's knowledge and/or their pregnancy outcomes were included. Additional information was obtained from authors of publications where required.

\section{Chart review}

Hospital records (in electronic and paper formats) of pregnant women with pre-gestational T1D $(n=53)$ and T2D $(n$ = 46) from Macarthur Diabetes in Pregnancy Clinic (MDPC), between 2010 and 2015, were reviewed. To minimise classification bias, medical records were re-reviewed. Data that were extracted from the charts included parity, age and body mass index (BMI), type of diabetes (type 1 vs. type 2 vs other), family history of diabetes, type of treatment (e.g. insulin, Metformin) at conception and during pregnancy, folate use, country of birth, third trimester HbA1c (\%), mode of delivery (e.g. vaginal, caesarean section, vacuum and forceps), as well 


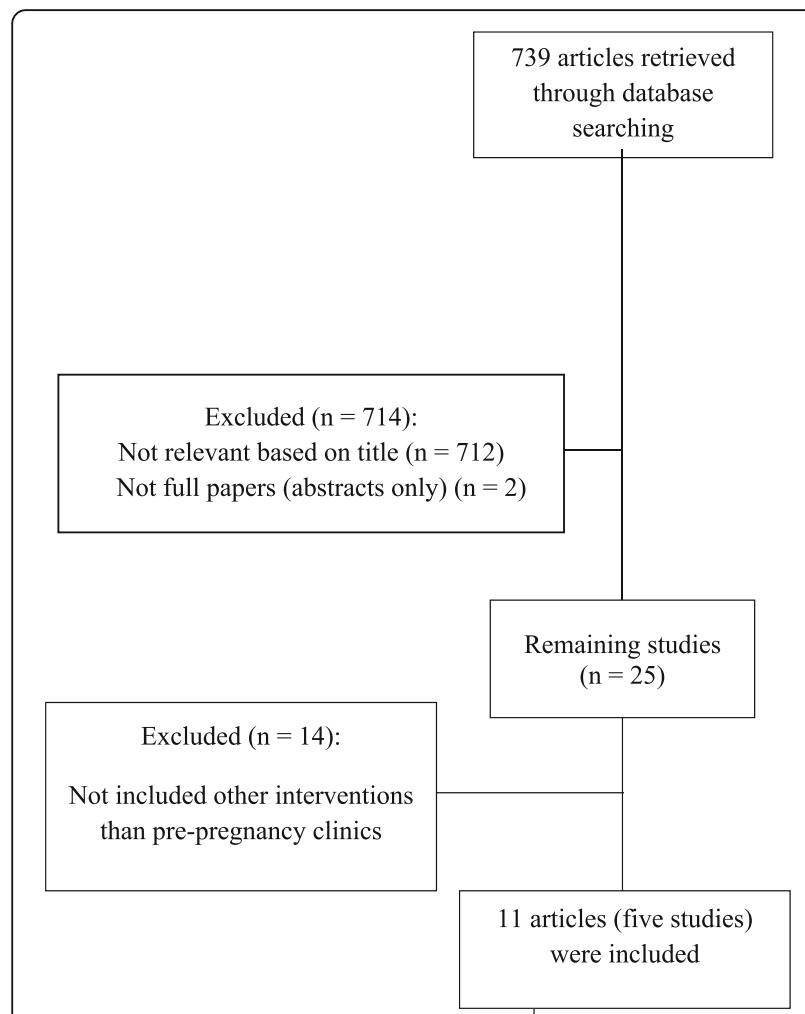

Fig. 1 Process of selection of the studies for the literature review

as pregnancy outcomes including neonatal hypoglycaemia, congenital malformations [15], macrosomia (birth-weight $\geq$ 4000 g or $>90 \%$ centile) [16], stillbirth, pre-eclampsia and hypertension (blood pressure $\geq 140 / 90 \mathrm{mmHg}$ ) [16].

\section{Interview surveys}

Fifteen women and $13 \mathrm{HCPs}$ were asked about their current and previous experiences of pre-pregnancy diabetes care/management and for suggestions to improve care, using closed and open questions either face to face or over the telephone. HCPs included General Practitioners (GPs) $(n=2)$, endocrinologists $(n=3$, private and 'public'), gynaecologists $(n=3)$, diabetes educators $(n=2)$, a dietitian $(n=1)$ and midwives $(n=2)$. Answers were summarised in relation to two identified over-arching key themes (contraception and PPM).

\section{Focus groups and one to one interviews}

Two separate focus groups were conducted involving two women with T1D, another including two women from CALD backgrounds (Muslim and Asian). Due to lack of flexibility in time for women and their partners to attend the focus-group sessions, 12 in-depth one-to-one interviews were also conducted using the same questions with women from an Australian background with T1D $(n=2)$ and T2D $(n=1)$, women with T2D of CALD background $(n=5)$ as well as partners of CALD women with T2D $(n=3)$, and an
Aboriginal woman with T2D $(n=1)$. Each focus group/ interview was audio recorded and transcribed verbatim.

\section{Development of a PPM plan}

The development of a draft PPM intervention plan was based on the identified approaches from the narrative review, using the components of previous studies (e.g. East Anglia Study group for Improving Pregnancy Outcomes in women with Diabetes (EASIPOD) [5]) and was then amended addressing gaps identified from the results of the chart-review, interview surveys and focus groups/interviews (Table 3). The plan components were shared in a local conference comprising multi-disciplinary HCPs and researchers. The attendees voted for each component based on feasibility, practicality and sustainability. The draft proposal was then discussed in two face-to-face meetings using a Delphi approach $[17,18]$. The first focussed on the perspective from primary care, including GPs $(n=12)$; a dietitian $(n=1)$ and endocrinologists $(n=2)$. Each proposed PPM/ contraception component was evaluated using a pros and cons list.

The final meeting involved key stakeholders from across the district (each of the 5 hospital facilities and primary care) representing a range of views from endocrinologists $(n=4)$, a diabetes educator, midwives $(n=5)$, obstetricians/gynaecologists $(n=2)$, a GP, a dietician, a clinical manager and health economists $(n=2)$. The meeting was facilitated by an endocrinologist. Those present formed three groups: two hospital facility groups and 'the rest' to discuss possible components of the intervention that related to their facility/perspective (Fig. 2). Once all groups reached consensus for each component of the program, responses were debated across the meeting, creating an opportunity for open discussion and combining or modifying the group outcomes. The final plan arose from this meeting.

\section{Analyses}

In the chart review, demographic characteristics and pregnancy outcomes among women with T1D and T2D were compared using chi-squared (categorical data) and $t$-tests (numerical data). Multivariate analyses (logistic regression and linear regression) were performed to adjust for age to compare the differences in characteristics between women with T1D and T2D. All analyses were performed using Stata v14. All tests were 2-tailed and significance was taken as $P<0.05$.

Qualitative data from the open-ended interview survey questions, focus groups and individual interviews were thematically analysed identifying topics and substantive categories within participants' accounts in relation to the study objectives. This helped to identify topical responses 

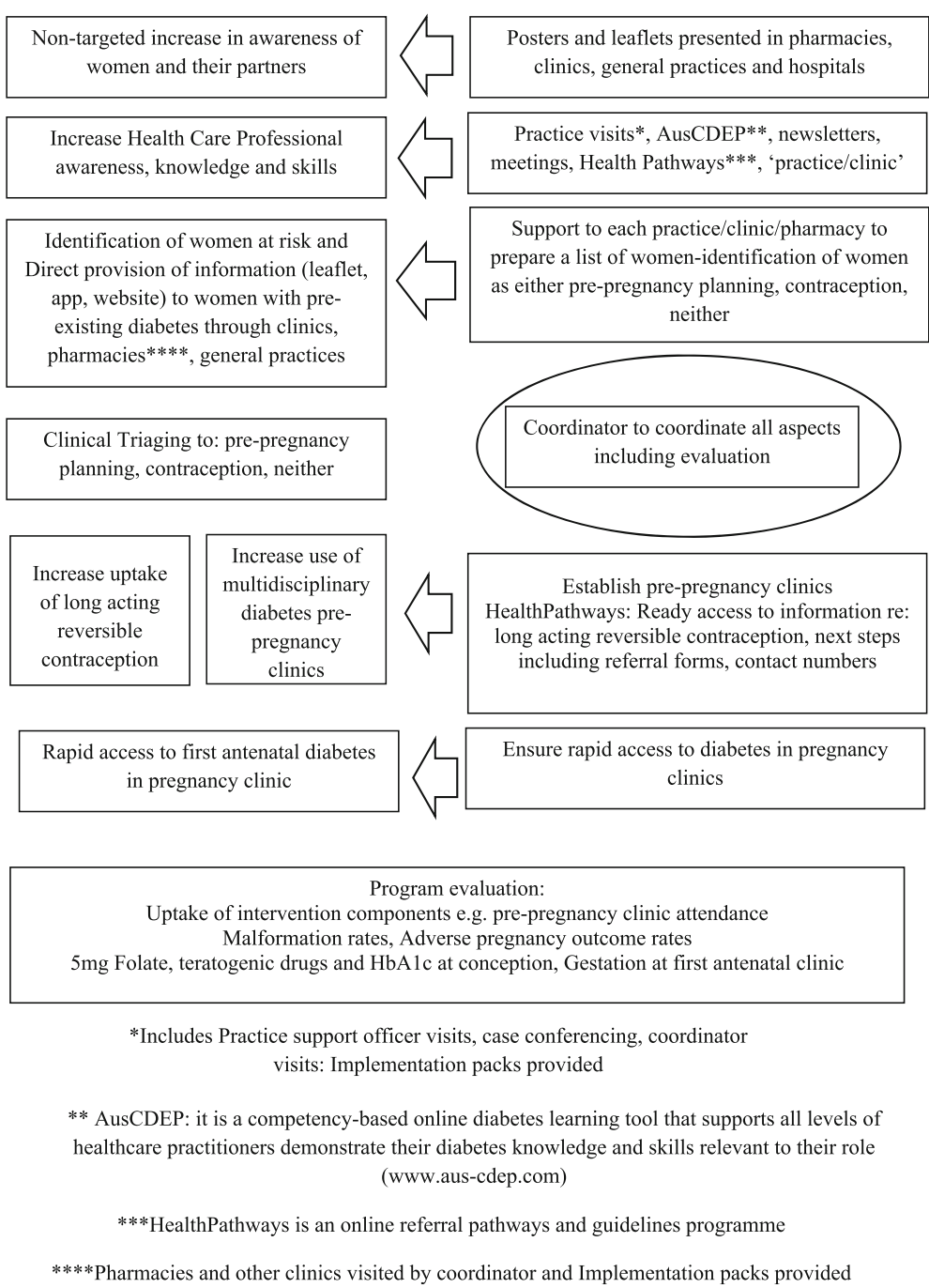

Fig. 2 The process of implementing the Diabetes Contraception and Pre-pregnancy Program

and emergent substantive categories, coding particularly for word repetition, direct and emotional statements and discourse markers including intensifiers, connectives and evaluative clauses. Responses and quotes from individuals participating in focus groups and interviews and responding to open ended questions from the interview surveys, are shown by alphanumeric coding, where women are labelled ' $\mathrm{W}$ ' and men ' $\mathrm{M}$ ' and the type of diabetes is indicated (e.g. W102- T1D = participant 102 who was a woman with type 1 diabetes).

\section{Results}

\section{Narrative review}

Figure 1 shows the number of studies identified and reasons for exclusion in the narrative review. As shown, from 739 studies, 714 studies were excluded in the first screening phase. One further publication emerged following the review [19]. As shown in
Table 1, five studies (published in 11 articles), which assessed different aspects of each type of intervention, were identified. Of the five studies, four used multi-faceted approaches (e.g. books, CD-ROM, posters, leaflets, HCP educational courses, counselling sessions, online learning materials for HCPs) [5, 9, 12, 19-22] and one used a mono-faceted approach (DVDs) [10, 13, 23, 24]. All approaches contained information on the importance of pregnancy planning, use of contraception, maternal and baby risk, and PPM components $[10,13,19,23,24]$.

Table 1 summarises the impact of four approaches on adverse pregnancy outcomes and/or knowledge of PPM. DVDs, the READY-Girls and the EASIPOD interventions improved the knowledge of women in pregnancy planning and contraception use [21] [23], and in PPM [12, 13]. Multi-faceted interventions (i.e. EASIPOD and leaflets and posters in healthcare facilities) decreased the rate of 


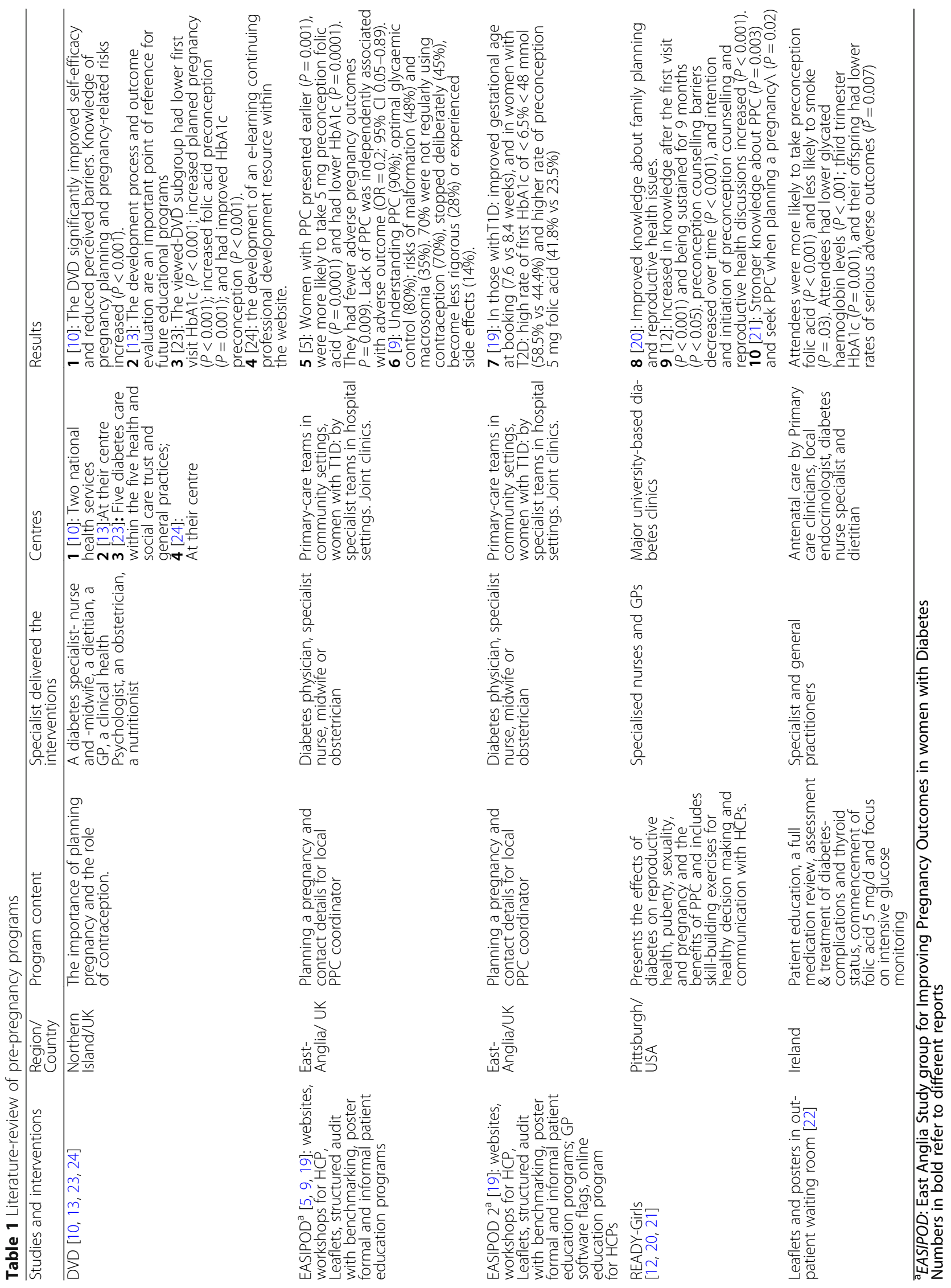


smoking [21], reduced HbA1c $[5,9,22])$ and increased 5 -mg folic-acid uptake $[5,9,22]$ at conception. The rates of adverse pregnancy outcomes including congenital malformations $(7.3 \%$ vs. $4.3 \% ; P=0.04)$ [9]; $(0.8 \%$ vs $5.2 \% ; P=0.04)$ [21] and perinatal mortality $(1.8$ vs. $3.7 \%, P=0.07)[9]$ were also significantly reduced. A revised EASIPOD programme (EASIPOD 2), in which primary diabetes practitioners were far more engaged, in addition to secondary healthcare providers, showed an increased rate of pre-conception $5 \mathrm{mg}$ folic-acid uptake (from 46 to $64 \%$ ) in women with T1D as well as significant improvement of HbA1c at conception in women with T2D, with almost $60 \%$ of women reaching target $(6.5 \%$ or $\leq 48 \mathrm{mmol} / \mathrm{mol})$ [19].

\section{Chart-review}

Table 2 shows that overall, women with diabetes were often overweight/obese, parous with a strong family history of diabetes. Women with T1D were largely (78.3\%) from Australia/ of European descent, with those with T2D from more varied backgrounds. High dose folic acid uptake was low, with no difference between women with Type 1 and Type 2 diabetes. Third trimester HbA1c was relatively high and several women $(9.5 \%)$ with T2D were medicating with potentially fetotoxic diabetes medications. Recorded retinal screening during pregnancy was low particularly (but non-significantly) in women with T2D. Malformation rates were high with an overall rate of $12.4 \%$. The overall rates of other pregnancy outcomes were also high including Caesarean section rates $(57.5 \%)$, hypoglycaemia $(24.5 \%)$, hypertension/preeclampsia (23.4\%) and macrosomia (29.8\%). While there were no stillbirths, women with T1D had a high miscarriage rate $(8.0 \%)$.

\section{Qualitative results (from interview surveys, focus groups and one to one interviews) Patients}

Early referral to the endocrinologist and clinic care (W102-T1D, W112-T2D), longer consultations and more frequent clinics (W105-T1D, W115-T1D), were highlighted as ways to improve the current service. Additional file 1 provides quotes reflecting each theme identified.Five women did not comment when asked how pre-pregnancy clinic care could be improved and a further three said no improvements were necessary.

Barriers to contraception and PPM included lack of awareness, limited motivation to change and/or a sense of information overload that reduced women's engagement with the education being provided to them. Most women took contraceptives until they were ready to become pregnant. However, they perceived the prepregnancy information they were provided was not pertinent until after they fell pregnant.
Women indicated that being aware of complications and having resources to assist them in leading a healthy life was important. Google was a common source of information that women felt was reliable (W109-T2D, W111-T2D, W103-T2D). However, those who solely relied on being educated by family and friends received incorrect information.

Partner support and investment were key to engagement with healthy lifestyle choices. Male partners were interested in enhancing their knowledge on pre-pregnancy diabetes management and contraception methods.

\section{HCPs}

HCPs utilised resources from a variety of sources to enhance their knowledge of PPM including specialists, self-education, information from professional organisations, meetings/seminars/conferences/ journal clubs, through personal experience and training courses. According to HCPs, the most common barriers to pre-pregnancy planning was lack of education/knowledge and unawareness of PPM in women.

Furthermore, HCPs suggested that advertisement and awareness of services (including mention of the power of word of mouth, use of TV screens in GP surgeries and leaflets distributed through pharmacies), incorporation of discussion about contraception and pregnancy planning with women with diabetes of child-bearing age, positive relationships with other HCPs, after-hours services, education of women from HCPs, support from the patient's partner, online services and more patient visits to GPs, could enhance PPM (Table 3). GPs highlighted the importance of referrals from primary to secondary care for PPM once women fall pregnant. GPs felt that the diabetes specialist services were best placed to provide the pre-pregnancy counselling.

\section{Development of the plan}

At the conference, HCPs agreed that all proposed components were practical and sustainable and should be included (Table 3). The subsequent HCP meetings led to reduced emphasis on any specially made media (e.g. DVD's) and GP checklist software (rather to include in existing software) due to their relatively high cost impact. Tables 4 and 5 show the items considered along with pros and cons of each component. The agreed core content for informational materials for both HCPs and women and their partners is shown in Table 6 .

Figure 2 shows the final components for the districtwide "Diabetes Contraception and Pre-pregnancy Program" (DCAPP) including the required resources and activities to be undertaken for the different target groups (women of childbearing age with T1D or T2D, women's partners and HCPs). This included establishing prepregnancy clinics and referral pathways, disseminating educational materials relating to both planning pregnancy 
Table 2 Characteristics and pregnancy outcomes of women with T1D and T2D from the chart review

\begin{tabular}{|c|c|c|c|c|c|}
\hline Variables & $\mathrm{T} 1 \mathrm{D}$ & $\mathrm{T} 2 \mathrm{D}$ & $P$-value & $\begin{array}{l}\text { T1D Melbourne } \\
(n=107)[29]\end{array}$ & $\begin{array}{l}\text { Background population } \\
\text { in NSW }{ }^{d}(2010) \text { [28] }\end{array}$ \\
\hline Age (years), mean (SD) & $28.6(5.6)$ & $32.9(5.2)$ & $<0.001$ & $29.3(5.3)$ & 30.8 \\
\hline$n=99$ & $n=53$ & $n=46$ & & & \\
\hline $\mathrm{BMI}^{\mathrm{a}}\left(\mathrm{Kg} / \mathrm{m}^{2}\right)$, mean $(\mathrm{SD})^{\mathrm{c}}$ & $25.8(5.2)$ & $35.4(8.1)$ & $<0.001$ & $\begin{array}{l}27.3(5.0) \\
--\end{array}$ & \\
\hline$n=93$ & $n=48$ & $n=45$ & & & \\
\hline Gravida, $n(S D)^{* *}$ & $2.6(2.2)$ & $3.1(2.2)$ & 0.17 & - & \\
\hline$n=98$ & $n=53$ & $n=45$ & & & \\
\hline Parity, n (SD) ${ }^{* *}$ & $1.0(1.2)$ & $1.5(1.4)$ & 0.09 & - & \\
\hline$n=98$ & $n=53$ & $n=45$ & & & \\
\hline Country of birth, $n(\%)^{* *}$ & & & $0.07^{* * *}$ & & \\
\hline Australia & $13(35.1)$ & $8(19.1)$ & & $95(89)$ & $67.3 \%$ \\
\hline European descent & $16(43.2)$ & $12(28.6)$ & & - & - \\
\hline India/Bangladesh & $1(2.7)$ & $5(11.9)$ & & - & $3.5 \%$ \\
\hline Aboriginal & $2(5.4)$ & $5(11.9)$ & & - & $3.3 \%$ \\
\hline Others & $5(13.5)$ & $12(28.6)$ & & - & $25.9 \%$ \\
\hline$n=79$ & $n=37$ & $n=42$ & & & \\
\hline Family history of diabetes, $n(\%)^{* *}$ & $20(66.7)$ & $30(83.3)$ & 0.30 & - & - \\
\hline$n=66$ & $n=30$ & $n=36$ & & & \\
\hline Third-trimester $\mathrm{HbA} 1 \mathrm{c}^{* *}$ & & & & - & - \\
\hline$\%$ & $7.0(1.8)$ & $6.5(1.4)$ & 0.4 & & \\
\hline $\mathrm{mmol} / \mathrm{mol}(\mathrm{SD})$ & $53.0(19.7)$ & $47.5(15.3)$ & & & \\
\hline$n=76$ & $n=39$ & $n=37$ & & & \\
\hline Folic acid, $n(\%)^{* *}$ & & & $0.4^{* * *}$ & & \\
\hline Nil & $13(36.1)$ & $9(30.0)$ & & & \\
\hline$<5 \mathrm{mg}$ & $7(19.4)$ & $8(26.7)$ & & & \\
\hline $5 \mathrm{mg}$ & $8(22.2)$ & $10(33.3)$ & & & \\
\hline Yes (dosage unknown) & $8(22.2)$ & $3(10.0)$ & & & \\
\hline$n=66$ & $n=36$ & $n=30$ & & & \\
\hline Treatment before pregnancy, $n(\%)^{* *}$ & & & $<0.001^{* * *}$ & & \\
\hline Diet alone & 0 & $4(9.4)$ & & & \\
\hline Tablets & 0 & $11(26.2)$ & & & \\
\hline Metformin & 0 & $8(19.0)$ & & & \\
\hline Gliclazide & 0 & $3(7.1)$ & & & \\
\hline Janumet (Metformin + Sitagliptin) & 0 & $1(2.4)$ & & & \\
\hline Insulin & $51(96.2)$ & $16(38.1)$ & & & \\
\hline Insulin + Metformin & $2(3.8)$ & $7(16.7)$ & & & \\
\hline Nil & 0 & $4(9.4)$ & & & \\
\hline$n=95$ & $n=53$ & $n=42$ & & & \\
\hline Treatment during pregnancy, $\mathrm{n}(\%)^{* *}$ & & & $0.003^{* * *}$ & & \\
\hline Insulin & $38(92.7)$ & $32(78.1)$ & & & \\
\hline Metformin & $1(2.4)$ & $2(4.9)$ & & & \\
\hline Insulin \& metformin & $1(2.4)$ & $5(12.2)$ & & & \\
\hline
\end{tabular}


Table 2 Characteristics and pregnancy outcomes of women with T1D and T2D from the chart review (Continued)

\begin{tabular}{|c|c|c|c|c|c|}
\hline Variables & T1D & $\mathrm{T} 2 \mathrm{D}$ & $P$-value ${ }^{*}$ & $\begin{array}{l}\text { T1D Melbourne } \\
(n=107)[29]\end{array}$ & $\begin{array}{l}\text { Background population } \\
\text { in } \mathrm{NSW}^{\mathrm{d}}(2010) \text { [28] }\end{array}$ \\
\hline$C S \|^{b}$ & $1(2.4)$ & 0 & & & \\
\hline Insulin only at labour & 0 & $1(2.4)$ & & & \\
\hline Total & $41(100)$ & $40(97.6)$ & & & \\
\hline$n=82$ & $n=41$ & $n=41$ & & & \\
\hline Retinopathy screening, n (\%) & & & $0.06^{* * *}$ & & \\
\hline Yes & $18(64.3)$ & $9(39.1)$ & & & \\
\hline No & $10(43.5)$ & $14(60.9)$ & & & \\
\hline$n=55$ & $n=29$ & $n=26$ & & & \\
\hline Thyroid disease, $n(\%)^{* *}$ & & & $0.8^{* * *}$ & & \\
\hline Yes & $6(12.0)$ & $5(11.9)$ & & & \\
\hline No & $42(84)$ & $36(85.7)$ & & & \\
\hline$n=89$ & $n=48$ & $n=41$ & & & \\
\hline Delivery methods ${ }^{\mathrm{b}}, \mathrm{n}(\%)^{* *}$ & & & $0.005^{* * *}$ & & \\
\hline Vaginal & $12(24.5)$ & $18(41.9)$ & & & \\
\hline Elective $\mathrm{CS}^{\mathrm{C}}$ & $17(34.7)$ & $13(30.2)$ & & & \\
\hline Emergency $\mathrm{CS}^{\mathrm{C}}$ & $11(22.5)$ & $9(20.9)$ & & & \\
\hline Vacuum & $3(6.1)$ & $4(9.3)$ & & & \\
\hline$n=87$ & $n=43$ & $n=44$ & & & \\
\hline \multicolumn{6}{|l|}{ Pregnancy outcomes ${ }^{\varphi}, n(\%)^{* *}$} \\
\hline Neonatal Hypoglycaemia & $9(36.0)$ & $3(12.5)$ & 0.12 & - & - \\
\hline$n=49$ & $n=25$ & $n=24$ & & & \\
\hline Any congenital malformations & $4(9.1)$ & $7(15.6)$ & 0.25 & $4(4)$ & $775(0.8)$ \\
\hline Major & $4(9.1)$ & $4(8.9)$ & 0.55 & - & - \\
\hline Minor & 0 & $4(8.9)$ & - & - & - \\
\hline$n=89$ & $n=44$ & $n=45$ & & & \\
\hline Hypertension & $11(24.4)$ & $10(22.2)$ & 0.25 & $2(2)$ & $6357(6.7)$ \\
\hline$n=90$ & $n=45$ & $n=45$ & & & \\
\hline Pre-eclampsia & $6(12.2)$ & $4(10.3)$ & 0.84 & $5(5)$ & - \\
\hline$n=88$ & $n=49$ & $n=39$ & & & \\
\hline Macrosomia (birthweight> $4000 \mathrm{~g}$ ) & $17(34.7)$ & $11(24.4)$ & $0.50^{\gamma}$ & $47(44)$ & - \\
\hline$n=94$ & $n=49$ & $n=45$ & & & \\
\hline Stillbirth & 0 & 0 & - & $7(7)$ & $555(0.6)$ \\
\hline$n=88$ & $n=48$ & $n=40$ & - & & - \\
\hline Miscarriage & $4(8.0)$ & 0 & & - & \\
\hline$n=94$ & $n=50$ & $n=44$ & & & \\
\hline
\end{tabular}

${ }^{\mathrm{a} B M I}$ body mass index; ${ }^{\mathrm{b}} \mathrm{CSI} / \mathrm{continuous} \mathrm{subcutaneous}$ insulin infusion; ${ }^{\mathrm{c} C S}$ Caesarean section; ${ }^{\mathrm{d}} \mathrm{NSW}$ New South Wales

*Age was included in all the statistical models;

** denominators vary due to missing values;

*** Overall $P$-value

$\phi$ those with miscarriage were excluded from the analyses $(n=4)$;

$\checkmark$ adjusted for age, $B M l$ and history of macrosomia

and avoiding unplanned pregnancies (contraception) for the woman, her partner and HCPs using a multitude of approaches including sending materials directly to the women, and establishing a programme to monitor uptake.
A key resource is the coordinator (may be more than one person), who will be appointed to oversee all aspects of the program including the educational program, data management and identifying/developing strategies to 
Table 3 Current gaps in adherence to optimal care, possible interventions and actions required for developing the interventions in South Western Sydney based on HCPs'a and women/partners inputs

\begin{tabular}{lll}
\hline Gaps (requirements) & $\begin{array}{l}\text { Intervention programs used in the literature/ } \\
\text { suggested by HCP's/women/partners }\end{array}$ & Actions required to implement the interventions \\
\hline $\begin{array}{l}\text { Lack of time for women/patients to attend } \\
\text { diabetes clinic }\end{array}$ & $\begin{array}{l}\text { Websites, leaflets, contact details of local HCPs } \\
\text { [5], social media }\end{array}$ & $\begin{array}{l}\text { 1) Providing after- hours clinics } \\
\text { 2) Providing other educational resources (e.g. } \\
\text { webpages, social media, and apps) } \\
\text { 3) Reaching out to all patients and mailing them } \\
\text { leaflets and information sheets on a regular basis }\end{array}$ \\
$\begin{array}{lll}\text { Lack of communication (miscommunication) } \\
\text { between HCPs and patients }\end{array}$ & $\begin{array}{l}\text { Workshops, newsletters, online learning } \\
\text { resources,regular meetings and } \\
\text { education programs [46] }\end{array}$ & $\begin{array}{l}\text { 1) Reminding HCPs about online resources and } \\
\text { workshops }\end{array}$ \\
& & $\begin{array}{l}\text { 2) Adding techniques for communication to the } \\
\text { existing learning materials }\end{array}$
\end{tabular}

Lack of knowledge about PPM and contraception methods in women and their partners
Leaflets, posters, DVDs, PPM education programs and peer support

Use of a wide range of interventions (e.g. online resources, social media, leaflets and posters)
1) Developing a wide range of educational resources (e.g. posters, apps)

2) Increasing the accessibility of educational resources

3) Translating educational resources in most common languages

Raising awareness among patients and their partners about the ranges of interventions address 'hard to reach' women. The coordinator will additionally visit hospital clinics, general practices, pharmacies and relevant clinics (e.g. fertility clinics), to deliver and discuss implementation packs tailored to each of the four settings. General practices will also be informed of the DCAPP through visits by the local Primary Health Network Practice Support Officers and local case-conferencing (where an endocrinologist visits practices to advise on the care of individual patients with diabetes). Pharmacies will also be visited by the DCAPP coordinator and medical students.

Implementation packs include asking HCPs at each venue to, display posters, have leaflets available, show DCAPP information on TV screens, if available, and undertake brief online training about pre-pregnancy planning (AusCDEP - a competency based online multiple choice based training tool). Practice and clinic staff will be given information on how to access HealthPathways (the local online referral and clinical guideline portal) for diabetes contraception/pre-pregnancy information, patient/partner printable materials and referral advice. All staff will be asked to explain the DCAPP (briefly), offer a DCAPP leaflet to each woman of reproductive age with diabetes and ask the woman to enrol (by text, email, DCAPP website and Facebook or Instagram) to access further materials, for an annual DCAPP update and to receive any new information should it arise. How this occurs will vary by setting:

- Pharmacists will be asked to approach those picking up diabetes prescriptions.

- GP surgeries, private fertility and public diabetes clinics will be requested to make a list of the women with T1D/T2D of reproductive age and provide the coordinator with this number. This may be facilitated by using practice software. The hospital clinics have been provided with BIOGRID database/ software [25] to facilitate this process. A clinic/ practice member will be identified as the contact person to provide/receive further information. General practice and diabetes clinic staff who see the women will be asked to record if a leaflet has been provided, and their assessment of whether the woman is

- planning to become pregnant (and therefore warrant pre-pregnancy management/referral to the prepregnancy clinics or private care)

- not planning to become pregnant and identify the form of contraception in place including abstinence or not required (e.g. hysterectomy, confirmed menopause)

- neither and listing reason including informed decision, religious reasons, not currently sexually active.

The contact person will be asked to maintain an internal register of leaflets provision, pre-pregnancy and contraception status and to provide a summary to the coordinator on a regular basis (quarterly). After the first round of approaches, the assessment would occur at each annual review (unless status changes beforehand).

All HCPs will also be invited to workshops/presentations run by their organisation/professional groups to allow further dissemination and discussion about the DCAPP (One of these has already occurred with 112 general practitioners attending). 
Table 4 Evaluation of interventions proposed for enhancement of Pre-Pregnancy Management (PPM) based on weighing pros and cons items

\begin{tabular}{|c|c|c|c|c|c|}
\hline Interventions & Content/ details & Places (to be implemented) & Pros & Cons & Included \\
\hline Workshops for HCPs ${ }^{a}$ & $\begin{array}{l}\text { Interpersonal techniques for } \\
\text { communicating with other } \\
\text { HCPs and patients (including } \\
\text { CALD }^{b} \text { women), and PPM }\end{array}$ & $\begin{array}{l}\text { Primary and secondary care } \\
\text { services }\end{array}$ & $\begin{array}{l}\text { Motivational, } \\
\text { Enhancing skills and } \\
\text { knowledge }\end{array}$ & $\begin{array}{l}\text { Lack of flexibility } \\
\text { in time, expensive }\end{array}$ & Yes \\
\hline DVD & $\begin{array}{l}\text { 'Risk of unplanned pregnancy, } \\
\text { and effective contraception } \\
\text { methods', 'local support team', } \\
\text { 'blood glucose targets, hypos } \\
\text { and ketoacidosis', 'diet, } \\
\text { delivery' and 'post-birth' }\end{array}$ & $\begin{array}{l}\text { Primary and secondary care } \\
\text { services including pharmacies }\end{array}$ & $\begin{array}{l}\text { Easily accessible and } \\
\text { convenient }\end{array}$ & $\begin{array}{l}\text { High cost, not } \\
\text { sustainable (can } \\
\text { be lost/or scratched) }\end{array}$ & No \\
\hline $\begin{array}{l}\text { Web-based education } \\
\text { program }\end{array}$ & $\begin{array}{l}\text { PPM information, links to pre- } \\
\text { existing YouTube channels in } \\
\text { multiple languages e.g. Arabic } \\
\text { and Vietnamese }\end{array}$ & Websites and social media & $\begin{array}{l}\text { Easily accessible and } \\
\text { convenient, no limits } \\
\text { in content }\end{array}$ & Passive & Yes \\
\hline $\begin{array}{l}\text { Courses for patients } \\
\text { and their partners }\end{array}$ & $\begin{array}{l}\text { The importance of PPM (e.g. } \\
\text { glycaemic control, smoking } \\
\text { cessation and physical activity) } \\
\text { and use of effective } \\
\text { contraception }\end{array}$ & $\begin{array}{l}\text { Primary and secondary care } \\
\text { services, women's } \\
\text { health clinics }\end{array}$ & $\begin{array}{l}\text { Motivational, they } \\
\text { can ask questions }\end{array}$ & $\begin{array}{l}\text { High cost, lack of } \\
\text { flexibility in time }\end{array}$ & No \\
\hline $\begin{array}{l}\text { Posters presentation } \\
\text { /T.V screen } \\
\text { advertisement }\end{array}$ & $\begin{array}{l}\text { The importance of PPM with } \\
\text { information about available } \\
\text { local services (contact details } \\
\text { for local HCPs) }\end{array}$ & $\begin{array}{l}\text { Waiting rooms of primary } \\
\text { and secondary care services, } \\
\text { pharmacies, women's health } \\
\text { and fertility clinics }\end{array}$ & $\begin{array}{l}\text { Easily visible, } \\
\text { encourage an } \\
\text { active response }\end{array}$ & Limited content & Yes \\
\hline $\begin{array}{l}\text { Peer support/web } \\
\text { chat }\end{array}$ & $\begin{array}{l}\text { Sharing experiences about } \\
\text { diabetes in pregnancy and } \\
\text { services they have used }\end{array}$ & DCAPP social media & $\begin{array}{l}\text { Easily accessible and } \\
\text { convenient }\end{array}$ & $\begin{array}{l}\text { Possibility of } \\
\text { inaccuracy } \\
\text { (Vulnerable to } \\
\text { (cognitive) biases) }\end{array}$ & Yes \\
\hline $\begin{array}{l}\text { Text message } \\
\text { reminders }\end{array}$ & $\begin{array}{l}\text { Links to the important websites, } \\
\text { available resources (e.g. local } \\
\text { pre-pregnancy clinics, } \\
\text { social media) }\end{array}$ & $\begin{array}{l}\text { Will be sent from the GP } \\
\text { practices on regular bases } \\
\text { (every six weeks) }\end{array}$ & $\begin{array}{l}\text { Easily accessible and } \\
\text { convenient }\end{array}$ & High cost & No \\
\hline Leaflets & $\begin{array}{l}\text { Links to useful websites, } \\
\text { potential risks of unplanned } \\
\text { pregnancy and risk factors for } \\
\text { potential complications }\end{array}$ & $\begin{array}{l}\text { Primary and secondary care } \\
\text { services, mail, pharmacies } \\
\text { and women's health clinics }\end{array}$ & Easy to access & $\begin{array}{l}\text { High cost (if mailed), } \\
\text { lack of interest (so } \\
\text { common) }\end{array}$ & Yes \\
\hline Apps & $\begin{array}{l}\text { 'Risk of unplanned pregnancy, } \\
\text { and effective contraception } \\
\text { methods', 'local support team', } \\
\text { 'blood glucose targets, hypos' } \\
\text { and ketoacidosis', 'diet, delivery' } \\
\text { and 'post-birth' }\end{array}$ & $\begin{array}{l}\text { DCAPP website and social } \\
\text { media, leaflets, and posters }\end{array}$ & $\begin{array}{l}\text { Systematic approach, no } \\
\text { cost to design } \\
\text { (already existed) }\end{array}$ & $\begin{array}{l}\text { Only available to } \\
\text { smart-phone users }\end{array}$ & Yes \\
\hline Social media & $\begin{array}{l}\text { Useful websites (e.g. NDSS }{ }^{d} \text { ), } \\
\text { updates/posts on the } \\
\text { importance of PPM and } \\
\text { contraception, and } \\
\text { YouTube channel }\end{array}$ & $\begin{array}{l}\text { Online (i.e. Facebook and } \\
\text { Instagram) }\end{array}$ & $\begin{array}{l}\text { High chance of } \\
\text { being visited } \\
\text { regularly }\end{array}$ & $\begin{array}{l}\text { Only available to } \\
\text { DCAPP social media } \\
\text { followers }\end{array}$ & Yes \\
\hline $\begin{array}{l}\text { Checklist software for } \\
\text { general practitioners }\end{array}$ & $\begin{array}{l}\text { Medication review, } \\
\text { contraception advice, weight } \\
\text { management strategies, } \\
\text { importance of having optimal } \\
\text { glycaemic control }\end{array}$ & GP surgeries & Systematic approach & $\begin{array}{l}\text { High cost of design } \\
\text { Needs to articulate } \\
\text { with existing software }\end{array}$ & No \\
\hline
\end{tabular}

${ }^{\mathrm{a}} H C P$ s: health care professionals

${ }^{\mathrm{b}} \mathrm{CALD}$ : culturally and linguistically diverse

${ }^{C} P P M$ : pre-pregnancy management

dNDSS: National Diabetes Service Scheme: An initiative of the Australian Government administered with the assistance of Diabetes Australia [47]

DCAPP Evaluation $[26,27]$

Evaluation will include assessment of uptake of the various components, qualitative evaluation of the perspectives of women, their partners and HCPs, a health economic evaluation and a comparison of pregnancy preparation and outcome measures over the first 12-24 months with those from the prior 6 years. 
Table 5 Interventions to increase contraception uptake- Pros and cons based on literature as well as conference and survey/focus group discussions

\begin{tabular}{|c|c|c|c|c|c|}
\hline Interventions & Content/ details & Places (to be implemented) & Pros & Cons & Included \\
\hline $\begin{array}{l}\text { Workshops for HCPs } \\
\text { and pharmacies [48] }\end{array}$ & $\begin{array}{l}\text { Available contraceptive methods } \\
\text { for women with diabetes and } \\
\text { insertion techniques for IUD }\end{array}$ & $\begin{array}{l}\text { Primary and secondary care } \\
\text { services and pharmacies }\end{array}$ & $\begin{array}{l}\text { Potentially motivates HCPS, } \\
\text { updates their knowledge }\end{array}$ & $\begin{array}{l}\text { Lack of flexibility in } \\
\text { time, High cost }\end{array}$ & Yes \\
\hline $\begin{array}{l}\text { Courses for patients } \\
\text { and their partners }\end{array}$ & $\begin{array}{l}\text { The importance of planning for } \\
\text { pregnancy and available } \\
\text { contraception options for } \\
\text { women with diabetes }\end{array}$ & $\begin{array}{l}\text { Primary and secondary care } \\
\text { services and pharmacies }\end{array}$ & $\begin{array}{l}\text { Potentially motivates } \\
\text { patients and their partners, } \\
\text { they can ask questions }\end{array}$ & $\begin{array}{l}\text { Lack of flexibility } \\
\text { in time, High cost }\end{array}$ & No \\
\hline $\begin{array}{l}\text { Accessibility of } \\
\text { contraception }\end{array}$ & $\begin{array}{l}\text { Providing free condoms in } \\
\text { health-care services (especially } \\
\text { primary care centres) }\end{array}$ & $\begin{array}{l}\text { Primary and secondary care } \\
\text { services, dental clinics, } \\
\text { women's health clinics, NDSS }\end{array}$ & $\begin{array}{l}\text { Easily visible, encourages } \\
\text { people to use } \\
\text { contraception }\end{array}$ & High cost & No \\
\hline $\begin{array}{l}\text { Leaflets women and } \\
\text { their partners' } \\
\text { awareness [49] }\end{array}$ & $\begin{array}{l}\text { Importance of planning } \\
\text { pregnancy and contraception } \\
\text { uptake in women with diabetes }\end{array}$ & $\begin{array}{l}\text { Primary and secondary care } \\
\text { services, women's health } \\
\text { clinics and NDSS }\end{array}$ & $\begin{array}{l}\text { Minimises potential } \\
\text { conflicts which could } \\
\text { exist within the couples }\end{array}$ & High cost if mailed & Yes \\
\hline $\begin{array}{l}\text { Mass-media, } \\
\text { community and } \\
\text { interpersonal } \\
\text { channels [50] }\end{array}$ & $\begin{array}{l}\text { Benefits of IUD, wide range of } \\
\text { available contraception options, } \\
\text { importance of optimised diabetes } \\
\text { management prior to pregnancy }\end{array}$ & $\begin{array}{l}\text { Primary and secondary care } \\
\text { services, pharmacies and } \\
\text { women's health clinics }\end{array}$ & $\begin{array}{l}\text { Repetitions, accessible to } \\
\text { the majority of population } \\
\text { group }\end{array}$ & $\begin{array}{l}\text { High cost, not } \\
\text { usable/usable for } \\
\text { CALD women }\end{array}$ & No \\
\hline $\begin{array}{l}\text { Web-based program } \\
\text { including YouTube } \\
\text { channel }\end{array}$ & $\begin{array}{l}\text { The importance of planning for } \\
\text { pregnancy and role of } \\
\text { contraception, education of } \\
\text { contraception options }\end{array}$ & $\begin{array}{l}\text { The app will be addressed } \\
\text { on leaflets, posters }\end{array}$ & $\begin{array}{l}\text { Accessible anytime, } \\
\text { pre-existed }\end{array}$ & $\begin{array}{l}\text { Needs internet } \\
\text { connection }\end{array}$ & Yes \\
\hline $\begin{array}{l}\text { Checklist software } \\
\text { for HCPs }\end{array}$ & Contraception advice & $\begin{array}{l}\text { The link will be available } \\
\text { on leaflet and posters }\end{array}$ & $\begin{array}{l}\text { Potentially motivates HCPs, } \\
\text { updates their knowledge }\end{array}$ & $\begin{array}{l}\text { High cost } \\
\text { Needs to articulate } \\
\text { with existing } \\
\text { software }\end{array}$ & No \\
\hline
\end{tabular}

${ }^{\mathrm{a} H C P}$ : Health care professionals

bIUD: intrauterine device

'NDSS: National Diabetes Service Scheme [47]- An initiative of the Australian Government administered with the assistance of Diabetes Australia

Program uptake will be evaluated by detailed monitoring of HCP education (AusCDEP uptake, workshop attendance, case conferencing patients), number of HealthPathways visits/clicks, number of social media followers, leaflets sent, pharmacy registrations, practice/pharmacy/clinic participation, practice/clinic reports (leaflet distribution, assessment

Table 6 Agreed core content for informational materials for both HCPs and women and their partners

Why conception with poor glucose control and/or unsafe medications should be avoided

Contraception and family planning advice, with emphasis on the most effective contraception options (e.g. Long Acting Reversible Contraception and emergency contraception) to prevent unplanned pregnancies.

Emphasising the importance of glycaemic control using safe medications at least three months prior to conception

$5 \mathrm{mg}$ folic-acid uptake at least three months prior to pregnancy.

Avoidance/replacement of teratogenic drugs particularly for hypertension and dyslipidaemia

Importance of retinal, renal and vascular complication screening prior to conception

The risk of smoking during pregnancy

Online educational resources (e.g. National Diabetes Supply Scheme, Facebook and Instagram pages)

Contact details of local health services status and long acting reversible contraception uptake reports), pre-pregnancy clinic attendance and gestation (weeks) at attendance of antenatal clinic once pregnant.

Measures of pregnancy preparation will be assessed from antenatal clinic records including: $5 \mathrm{mg}$ folic acid uptake from at least 3-months preconception, whether this is a planned pregnancy or otherwise, use of potentially teratogenic medications at conception and gestational age at first visit. Other measures include first visit blood pressure, HbA1c, BMI and smoking status. Third trimester HbA1c will also be assessed.

Pregnancy outcomes will be collected from birth records including major and minor congenital malformations, stillbirths, neonatal trauma, emergency caesarean section, preeclampsia, prenatal mortality, miscarriage, preterm birth, small and large for gestational age, severe maternal hypoglycaemia, and gestational weight-gain [26, 27].

Process evaluation will include assessment of reach and the use of the DCAPP materials, through interviews in a purposeful sample of women of reproductive age with diabetes who have become pregnant (planned and unplanned) and received the materials, plus partners and HCPs. Interviews will include evaluation of the most effective mix of approaches (e.g. online and/or through pharmacies, hospital clinics and/or GP surgeries) for contacting and enrolling patients, identification of barriers 
and facilitators to implementation for each program component and aspects that both stimulate and obstruct use of DCAPP. Interviews will be repeated over time to facilitate continuous evaluation and quality management of the program.

Cost-effectiveness analysis will be conducted using the total intervention cost, summation of the different components, and benefits to New South Wales Health based on primary and secondary outcomes and their unit costs. An incremental analysis will be conducted for the women who had prior pregnancies. A full plan is currently under discussion.

\section{Discussion}

The rate of congenital malformations in this district (6.8$12.4 \%$ ) [1] is higher than that of the background population (1.7\%, from 2005 to 2010) [28], as well as the rates reported by two previous Australian studies conducted in Melbourne (4\%) [29] and Adelaide (5\%) [30] and several international studies from England, Wales, and Northern Ireland (4.6\%) [31] and from north west England (9.4\%) [32]. Similarly, the rate of preeclampsia is considerably higher in our study than that reported from Melbourne $(12.2 \%$ vs. $5.0 \%)$. However, the rates of macrosomia (34.7\%) and caesarean section (57.2\%) are slightly lower in our study than those reported by the study done in Melbourne ( $44 \%$ and $62 \%$, respectively) [28]. Our results showed few women $(2.4 \%)$ with T1D were receiving continuous subcutaneous insulin infusions (CSII) in comparison with those in the United Kingdom (20\%) [33, 34], which could be due to its out of pocket cost in Australia and HCP time requirements [35].A range of barriers have been identified, similar to those reported previously [36], that are likely to have contributed to limitations in clinical care and self-management. These in turn will have increased the likelihood of unplanned pregnancies and poor pregnancy outcomes (e.g. congenital malformations) [36, 37]. In view of the high rate of congenital malformations, and existing barriers to optimal care, the development and implementation of a district-wide contraception and pre-pregnancy program was considered to be an urgent initiative. The program does not address issues related to undiagnosed diabetes and its association with adverse pregnancy outcomes.

The DCAPP program is the first Australian diabetes pre-pregnancy intervention program based upon various research tools (comprehensive literature review, audits, interview surveys and in-depth focus-groups and interviews in addition to multidisciplinary meetings with $\mathrm{HCPs}$ ). It has targeted women's partners who can potentially influence women's PPM and contraceptive uptake decision making [38]. Furthermore, the program is based upon principles of integrated care, with a primary-secondary care partnership, including aspects of clinical care within primary care, rather than simple specialist/hospital educational interventions. The program has been developed to allow both sustainability and scalability. In the few places where such a comprehensive program has been put into place, malformations in particular were (cardiac, spinal) has been estimated to have a lifelong cost of $\$ 1,000,000$ [39].

As a program across a population of almost a million [40], over 450 general practices, 188 pharmacies and five hospitals with birthing facilities, DCAPP is faced with a range of challenges associated with large scale programs. As a result, the program will be implemented practice by practice, clinic by clinic and pharmacy by pharmacy with the support of other organisations including the Primary Health Network that supports all general practices across SWS. By including both general practices and pharmacies in the program, we expect to also reach those women with T1D/T2D who attend private providers (e.g. endocrinologists, educators) for their care. The degree of participation by those under the public and private sectors (and their pregnancy outcomes) will be included in the evaluation.

With such an extensive range of providers, the role of the coordinator, the DCAPP team and the within clinic/ practice contacts will also be crucial in identifying those reached or otherwise by the roll out and in developing new strategies to reach women who are hard to reach. For example, women with T2D on diet management alone might not attend pharmacies and may need additional practice based strategies. Evaluation of the uptake of the clinic/practice contact and their reporting will be important to identify the need for any further support/incentives for this role.

SWS is characterised by its rich cultural diversity (represented by residents from East and South Asia, the Middle East and the Pacific Islands) [40]. Of particular interest, as the program is rolled out, will be the uptake of contraception among cultural groups who may have religious objections to pharmacological or barrier contraception methods. This is likely to require additional work (e.g. a targeted optimisation program, including avoidance of potentially teratogenic agents) among women with T2D not taking contraception.

Myths and misconceptions as well as lack of knowledge of emergency contraception, and their male partners' perspectives regarding contraception, are the most common barriers to utilising contraception for women (especially in those with lower levels of education) [41-44]. Previous studies [44, 45] have also highlighted the important role of social media and group-session workshops in raising and updating women's knowledge of contraception uptake. Methods to achieve this are included as part of the DCAPP.

Our chart reviews and interviews/focus groups were limited due to small sample size/number of participants, leading to wide limits for the pregnancy outcomes and 
possible under-reporting the participants' comments and suggestions. Nevertheless, our results have shown the severity of poor pregnancy outcomes in women living in SWS, emphasising the need for an intervention program in this district.

\section{Conclusions}

With the high rates of congenital malformations and high ethnic diversity in this district of Sydney, it is hoped that this program will sustainably reduce adverse pregnancy outcomes in women with pre-existing T1D/ T2D. DCAPP is based upon formative research, current best practice, a partnership across primary and secondary care, with new facets including social media and information for partners that have not been included in previous PPM programs. The role of implementation, outcome and cost-effectiveness monitoring will be crucial to assess whether the program should be continued and extended to other areas.

\section{Additional file}

Additional file 1: Example excerpts reflecting the themes identfied. Perspectives of women and their partners on the barriers of prepregnancy management and contraception uptake and the importance of having access to additional educational resources. (DOCX $33 \mathrm{~kb}$ )

\section{Abbreviations}

BMI: Body mass index; DCAPP: Diabetes Contraception and Pre-pregnancy Program; EASIPOD: East Anglia Study group for Improving Pregnancy Outcomes in women with Diabetes; GP: General practitioner; HCP: Health care professional; PPC: pre-Pregnancy Care; PPM: Pre-Pregnancy Management; SWS: South Western Sydney; T1D: Type 1 diabetes; T2D: Type 2 diabetes

\section{Acknowledgements}

We thank patients and their partners, health care professionals and other health staff for their input. We thank Professor Helen Murphy and Deborah Hughes for the documentation from EASIPOD and EASIPOD2.

\section{Funding}

This project has been funded by South Western Sydney Local Health District with support from South Western Sydney Primary Health Network and the Sydney Partnership for Health Education Research and Enterprise.

\section{Availability of data and materials}

The datasets analysed during the current study are not publically available to maintain confidentiality of participants but are available from the corresponding author on reasonable request.

\section{Authors' contributions}

MS drafted the manuscript and conducted the literature-review, contributed to the quantitative data collection, data management and data analysis, performed focus-groups, some of the one-to-one interviews and contributed to the qualitative analysis. FM supervised interviews and performed focusgroups and part of the qualitative analysis. TD conducted the qualitative analysis for the focus-groups and interviews. NB, NN, NK, VJ and XHL carried out datacollection. DS conceived the overall program, chaired group meetings, supervised the work of MS, NB, NK, NN, VJ and XHL, designed Fig. 2 and revised the manuscript. All authors read and approved the final manuscript.

\section{Ethics approval and consent to participate}

Verbal consent from our participants was obtained before commencing telephone surveys and written consent for the focus-group sessions. Permission for having access to the de-identified patients' data was obtained from Campbelltown Hospital Clinical Information Department. Ethical approval was obtained from South Western Sydney Local Health District (SWSLH) (Reference \#: LNR/16/LPOOL/264)

\section{Competing interests}

The authors declare that they have no competing interests.

\section{Publisher's Note}

Springer Nature remains neutral with regard to jurisdictional claims in published maps and institutional affiliations.

Received: 26 February 2018 Accepted: 25 September 2018

Published online: 15 October 2018

\section{References}

1. Wong W, Suwandarathne $H$, Russell H. Women with pre-existing diabetes under the care of diabetes specialist prior to pregnancy: are their outcomes better? Aust N Z J Obstet Gynaecol. 2013;53(2):207-10.

2. Simmons D. Epidemiology of diabetes in pregnancy. London: Blackwell publishing; 2010.

3. Wahabi HA, Alzeidan RA, Esmaeil SA. Pre-pregnancy care for women with pre-gestational diabetes mellitus: a systematic review and meta-analysis. BMC Public Health. 2012;12:792.

4. Kikuchi K, Okawa S, Zamawe COF, Shibanuma A, Nanishi K, Iwamoto A, Saw YM, Jimba M. Effectiveness of continuum of care-linking pre-pregnancy care and pregnancy care to improve neonatal and perinatal mortality: a systematic review and meta-analysis. PLoS One. 2016;11(10):e0164965.

5. Murphy HR, Roland JM, Skinner TC, Simmons D, Gurnell E, Morrish NJ, Soo SC, Kelly S, Lim B, Randall J, et al. Effectiveness of a regional prepregnancy care program in women with type 1 and type 2 diabetes: benefits beyond glycemic control. Diabetes Care. 2010;33(12):2514-20.

6. O'Higgins $\mathrm{S}, \mathrm{McGuire} B \mathrm{BE}$, Mustafa E, Dunne F. Barriers and facilitators to attending pre-pregnancy care services: the ATLANTIC-DIP experience. Diabet Med. 2014:31(3):366-74.

7. Henshaw SK. Unintended pregnancy in the United States. Fam Plan Perspect. 1998:30(1):24-46.

8. Janz NK, Herman WH, Becker MP, Charron-Prochownik D, Shayna VL, Lesnick TG, Jacober SJ, Fachnie JD, Kruger DF, Sanfield JA, et al. Diabetes and pregnancy. Factors associated with seeking pre-conception care. Diabetes Care. 1995;18(2):157-65.

9. Murphy HR, Temple RC, Ball VE, Roland JM, Steel S, Zill EHR, Simmons D, Royce LR, Skinner TC. Personal experiences of women with diabetes who do not attend pre-pregnancy care. Diabet Med. 2010;27(1):92-100.

10. Holmes VA, Spence M, McCance DR, Patterson CC, Harper R, Alderdice FA. Evaluation of a DVD for women with diabetes: impact on knowledge and attitudes to preconception care. Diabet Med. 2012;29(7):950-6.

11. Charron-Prochownik D, Ferons-Hannan M, Sereika S, Becker D. Randomized efficacy trial of early preconception counseling for diabetic teens (READYgirls). Diabetes Care. 2008;31(7):1327.

12. Fischl AFR, Herman WH, Sereika SM, Hannan M, Becker D, Mansfield MJ, Freytag LL, Milaszewski K, Botscheller AN, Charron-Prochownik D. Impact of a preconception counseling program for teens with type 1 diabetes (READY-girls) on patient-provider interaction, resource utilization, and cost. Diabetes Care. 2010:33(4):701.

13. Spence M, Harper R, McCance D, Alderdice F, McKinley M, Hughes C, Holmes $V$. The systematic development of an innovative DVD to raise awareness of preconception care. Eur Diabetes Nurs. 2013;10(1):7-12b.

14. Malin M, Gissler M. Maternal care and birth outcomes among ethnic minority women in Finland. BMC Public Health. 2009;9(1):84.

15. Landon MB, Spong CY, Thom E, Carpenter MW, Ramin SM, Casey B, Wapner RJ, Varner MW, Rouse DJ, Thorp JM Jr, et al. A multicenter, randomized trial of treatment for mild gestational diabetes. N Engl J Med. 2009;361 (14):1339-48.

16. Feig DS, Corcoy R, Jensen DM, Kautzky-Willer A, Nolan CJ, Oats JJ, Sacks DA, Caimari F, McIntyre HD. Diabetes in pregnancy outcomes: a systematic review and proposed codification of definitions. Diabetes Metab Res Rev. 2015;31(7):680-90 
17. Gazing into the oracle. The Delphi method and its application to social policy and public health. London: Jessica Kingsley Publishers; 1996.

18. Sinha IP, Smyth RL, Williamson PR. Using the Delphi technique to determine which outcomes to measure in clinical trials: recommendations for the future based on a systematic review of existing studies. PLoS Med. 2011;8(1):e1000393.

19. Yamamoto JM, Hughes DJF, Evans ML, Karunakaran V, Clark JDA, Morrish NJ, Rayman GA, Winocour PH, Hambling C, Harries AW, et al. Community-based pre-pregnancy care programme improves pregnancy preparation in women with pregestational diabetes. Diabetologia. 2018;61(7):1528-37.

20. Charron-Prochownik D, Ferons-Hannan M, Sereika S, Becker D. Randomized efficacy trial of early preconception counseling for diabetic teens (READYgirls). Diabetes Care. 2008;31:1327-30.

21. Charron-Prochownik D, Sereika SM, Becker D, White NH, Schmitt P, Powell AB 3rd, Diaz AM, Jones J, Herman WH, Fischl AF, et al. Long-term effects of the booster-enhanced READY-girls preconception counseling program on intentions and behaviors for family planning in teens with diabetes. Diabetes Care. 2013;36(12):3870-4.

22. Egan AM, Danyliv A, Carmody L, Kirwan B, Dunne FP. A Prepregnancy care program for women with diabetes: effective and cost saving. J Clin Endocrinol Metab. 2016;101(4):1807-15.

23. Holmes VA, Hamill LL, Alderdice FA, Spence M, Harper R, Patterson CC, Loughridge S, McKenna S, Gough A, McCance DR. Effect of implementation of a preconception counselling resource for women with diabetes: a population based study. Prim Care Diabetes. 2017;11(1):37-45.

24. Gough A, McCance D, Alderdice F, Harper R, Holmes V. Preconception counselling resource for women with diabetes. BMJ Qual Improv Rep. 2015; 4(1):U209621-w3984.

25. BioGrid Australia-health through information. In. BioGrid Australia.

26. Egan AM, Galjaard S, Maresh MJA, Loeken MR, Napoli A, Anastasiou E, Noctor E, de Valk HW, van Poppel M, Todd M, et al. A core outcome set for studies evaluating the effectiveness of prepregnancy care for women with pregestational diabetes. Diabetologia. 2017;60(7):1190-6.

27. Kekalainen $\mathrm{P}$, Juuti $\mathrm{M}$, Walle $\mathrm{T}$, Laatikainen $\mathrm{T}$. Pregnancy planning in type 1 diabetic women improves glycemic control and pregnancy outcomes. J Matern Fetal Neonatal Med. 2016;29(14):2252-8.

28. Centre for Epidemiology and Evidence. New South Wales Mothers and Babies 2010. Sydney: NSW Ministry of Health; 2012.

29. Abell SK, Boyle JA, de Courten B, Knight M, Ranasinha S, Regan J, Soldatos G, Wallace EM, Zoungas S, Teede HJ. Contemporary type 1 diabetes pregnancy outcomes: impact of obesity and glycaemic control. Med J Aust. 2016;205(4):162-7.

30. Sharpe PB, Chan A, Haan EA, Hiller JE. Maternal diabetes and congenital anomalies in South Australia 1986-2000: a population-based cohort study. Birth Defects Res Part A: Clin Mol Teratol. 2005;73(9):605-11.

31. Macintosh MCM, Fleming KM, Bailey JA, Doyle P, Modder J, Acolet D, Golightly S, Miller A. Perinatal mortality and congenital anomalies in babies of women with type 1 or type 2 diabetes in England, Wales, and Northern Ireland: population based study. BMJ. 2006;333(7560):177.

32. Casson IF, Clarke CA, Howard CV, McKendrick O, Pennycook S, Pharoah POD, Platt MJ, Stanisstreet M, van Velszen D, Walkinshaw S. Outcomes of pregnancy in insulin dependent diabetic women: results of a five year population cohort study. BMJ. 1997;315(7103):275-8.

33. Egan AM, Murphy HR, Dunne FP. The management of type 1 and type 2 diabetes in pregnancy. QJM. 2015;108(12):923-7.

34. Pickup JC. Insulin-pump therapy for type 1 diabetes mellitus. N Engl J Med. 2012;366(17):1616-24.

35. Xu S, Alexander K, Bryant W, Cohen N, Craig ME, Forbes M, Fulcher G, Greenaway T, Harrison N, Holmes-Walker DJ, et al. Healthcare professional requirements for the care of adult diabetes patients managed with insulin pumps in Australia. Intern Med J. 2014;45(1):86-93.

36. Simmons D, Weblemoe T, Voyle J, Prichard A, Leakehe L, Gatland B. Personal barriers to diabetes care: lessons from a multi-ethnic community in New Zealand. Diabet Med. 1998;15(11):958-64

37. Nam S, Chesla C, Stotts NA, Kroon L, Janson SL. Barriers to diabetes management: patient and provider factors. Diabetes Res Clin Pract. 2011;93(1):1-9.

38. Forde $\mathrm{R}$, Patelarou EE, Forbes A. The experiences of prepregnancy care for women with type 2 diabetes mellitus: a meta-synthesis. Int J Women's Health. 2016;8:691-703.

39. Kruse M, Michelsen SI. Flachs EM, Bronnum-Hansen H, Madsen M, Uldall P. Lifetime costs of cerebral palsy. Dev Med Child Neurol. 2009;51(8):622-8.
40. Draft South West District Plan. In: Our vision -south West District 2036 Edited by Turnbull HL; 2016

41. Salisbury P, Hall L, Kulkus S, Paw MK, Tun NW, Min AM, Chotivanich K, Srikanok S, Ontuwong P, Sirinonthachai S, et al. Family planning knowledge, attitudes and practices in refugee and migrant pregnant and post-partum women on the Thailand-Myanmar border - a mixed methods study. Reprod Health. 2016;13(1):94

42. Richmond DM, Sabatini MM, Krueger H, Rudy SJ. Contraception: myths, facts, and methods. Dermatol Nurs. 2001;46(2):19-26.

43. Ezeanolue EE, Iwelunmor J, Asaolu I, Obiefune MC, Ezeanolue CO, Osuji A, Ogidi AG, Hunt AT, Patel D, Yang W, et al. Impact of male partner's awareness and support for contraceptives on female intent to use contraceptives in Southeast Nigeria. BMC Public Health. 2015;15:879.

44. Ochako R, Mbondo M, Aloo S, Kaimenyi S, Thompson R, Temmerman M, Kays M. Barriers to modern contraceptive methods uptake among young women in Kenya: a qualitative study. BMC Public Health. 2015;15:118.

45. Cupples JB, Zukoski AP, Dierwechter T. Reaching young men: lessons learned in the recruitment, training, and utilization of male peer sexual health educators. Health Promot Pract. 2010;11(3):19S-25S.

46. Rajashree KC. Training programs in communication skills for health care professionals and volunteers. Indian J Palliat Care. 2011;17(Suppl):S12-3.

47. National Institute for clinical Excellence (NICE) (Great Britain). Diabetes in pregnancy. In: Management of diabets and its complications from preconception to the postnatal period. London: PROG Press; 2015.

48. Simmons KB, Rodriguez MI. Reducing unintended pregnancy through provider training. Lancet. 2015;386(9993):514-6.

49. Phiri M, King R, Newell JN. Behaviour change techniques and contraceptive use in low and middle income countries: a review. Reprod Health. 2015;12:100.

50. Rattan J, Noznesky E, Curry DW, Galavotti C, Hwang S, Rodriguez M. Rapid contraceptive uptake and changing method mix with high use of longacting reversible contraceptives in crisis-affected populations in Chad and the Democratic Republic of the Congo. Global health, science and practice. 2016:4(2):S5-s20.

Ready to submit your research? Choose BMC and benefit from:

- fast, convenient online submission

- thorough peer review by experienced researchers in your field

- rapid publication on acceptance

- support for research data, including large and complex data types

- gold Open Access which fosters wider collaboration and increased citations

- maximum visibility for your research: over $100 \mathrm{M}$ website views per year

At $\mathrm{BMC}$, research is always in progress.

Learn more biomedcentral.com/submissions 